\title{
Research on the pricing strategy of the two-stage closed-loop supply chain with re-manufacturing
}

\author{
Xiao-Hao Liang, Zu-Qing Huang, Yu-Xiang Yang \\ College of Economics and Management, China JiLiang University, Hangzhou, China \\ E-mail: 1xh464008424@qq.com, hzq1210@163.com,yyx_bj2005@126.com
}

\begin{abstract}
With the enhancement of peoples' concepts that are environmental protection, sustainable development, recycling has aroused the attention of enterprises and scholars. Because of the difference between the acceptance of re-manufacturing products and the popularity of new products, these two products' pricing processes are different. This paper focuses on the product pricing of the re-manufacturing closed-loop supply chain, which consists a single manufacturer and seller. We assume that the manufacturer dominates the market in the two stages, in which only new products be manufactured in the first stage, both of the two kinds of products can be manufactured in the second stage. The results show that, in the second stage, sale prices of new products and re-manufacturing products are both lower than only produce new products. When we choose the former, it will obtain more benefits. Furthermore, the retailer will do better when more money was paid for waste products. And the manufacturer's wholesale price is determined by the cost of new products, recycled products and recycling price.
\end{abstract}

Keywords-closed-loop; supply chain; collection; re-manufacturing; reverse logistics; pricing decisions

\section{INTRODUCTION}

Re-manufacturing of used products is not a new term but the scale and unique processes have made re-manufacturing an important subject in research. Especially, with the construction of ecological civilization put forward, the acquisition of used products, called cores, for re-manufacturing becomes an important issue .Many companies try to implement re-manufacturing to get considerable economic benefits and social benefits, such as HP Company manufacture reusable printer cartridges ${ }^{[1]}$.

\section{II.LITERATURE REFERENCES}

There are a growing number of literature researches from different angles to analysis the problem about recycling and re-manufacturing products. Da qingli et al. (2004) [2] described the present situation of the reverse logistics system structure research, and prospected the direction of further research about reverse logistics in later. Savaskan R C et al. (2004)[3] supposed new manufacturing and re-manufacturing product price is the same, analyzes the closed-loop supply chain efficiency of three different structure, and found that retailers recovery efficiency is highest. Heese H S et al. (2005) [4] described the Oligarchic competitive advantage affect of recycling of waste products when closed-loop supply chain in monopoly environment.
Ferguson et al. (2006) [5] studied the competition between new products and re-manufacturing products, which affect the manufacturer pricing strategy. Huang zuqing et al. (2006)[6] studied the supply chain benefits of manufacturer or the third party that is responsible to recycle of closed-loop supply chain under the different decision structure. Wang wenbin et al. (2009)[7] established the closed-loop supply chain model according to the market segmentation, analyzed the decision variables changed by the exogenous variables, and compares the production and pricing strategy under the closed-loop supply chain and not recycled manufacturing situation. Liang et al. (2009) [8] studied the problem of re-manufacturing product pricing under the assumption that sales price follows geometric Brownian motion (GBM). Xie jiaping et al. (2011) [9] described the re-manufacturing model with production constraint under the market preferences, and analyzed the optimal production and price decisions strategy under two production cycle and indefinitely. In summary, most of the existing research is proposed to compare advantages between re-manufacturing products and new products, and supposed that the remanufacturing products and new products appear at the same time, however, only when new products are sold after the first phase, the number of waste products could accumulate. Therefore, it would have enough corresponding materialstore-manufacture products at the second stage.

Giutini et al. (2007)[10] mentionedre-manufacturing product usually adopt high quality technical standards, which makes the new product and re-manufacturing product more and more close to in terms of quality. Due to the lower price, the manufacture products will be more popular than the new products in the market. It will lead the re-manufacture products occupy with the market and change the market position of new product, breaking the original production profit model.

This paper is based on the actual situation and discusses the different pricing strategies:1.What kind of price strategy can make the enterprise gain maximum profit when they decide to only manufacture new products in two stages under the "single manufacturer and a single seller" of closed-loop supply chain system? 2. What kind of price strategy can make the enterprise gain maximum profit when they decide tomanufacture new products and re-manufacturing products in the second stage? 3. Which is the best strategy for the manufacturer and retailer in the two stages? In other words, we will answer whether need to let re-manufacturing production process introduced into the actual process. 


\section{MODEL ASSUMPTIONS AND NOTATION}

According to the Savaskan et al. (2004) [3], which indicated the seller is responsible to recycle the highest efficiency of closed loop supply chain structure. So we rely on this conclusion and use the following notation throughout the paper: $c_{n}$ will denote the unit cost of manufacturing a new product, and $c_{r}$ the unit cost of re-manufacturing a returned product into a new one. $w_{n}$ is the unit wholesale price of a new product, $w_{r}$ is the unit wholesale price of re-manufacturing a returned product into a new one. $p_{n}$ is the unit retail price of a new product, $p_{r}$ is the unit retail price of a re-manufacturing product. $b$ will denote the unit transfer price of a returned product from the consumer to the retailer and B will denote the unit transfer price of a returned product from the retailer to the manufacturer.

The primary goal of this paper is to understand the pricing strategy between two different production stages. Hence, we consider the following scenario and make the following model assumptions.

Suppose that the manufacture has incorporated a re-manufacturing process for used products into her original production system when they decide to product re-manufacturing products in the second cycle, so that she can manufacture a new product directly from raw materials, or re-manufacture part or whole of a returned unit into new products.

Assumption 1.Manufacturing new products by using a used productsare less costly than manufacturing a new one, i.e., $c_{n}>c_{r}$ and $c_{r}$ is the same for all re-manufactured products. Returned product from the consumer to the retailer is less costly than returned product from the retailer to the manufacturer.

Assumption2. In the closed-loop supply chain, the manufacturers and sellers due to various factors, sometimes the manufacturers dominate the market, while sometimes the sales dominate the market. In order to make the result more precise, this paper assumes that manufacturers are the market leader.

Assumption 3.In this paper, we assume that all the products returned by the retailer. Therefore, the quantity equation of returned products is expressed: $g=\lambda q_{1 n}+\delta b$. $\lambda$ will denote the proportion of consumer consciousness returns of waste products $\delta$ will denote effort coefficient which means manufacturers use the high price to incentive sellers more recycling efforts. $r$ will denote the proportion of the returned products. $S$ will denote the unit value of the rest waste products.

Assumption 4. In the first stage, the manufacturers make new products and saleby the seller. The demand for new products' equation is expressed: $q_{1 n}=\alpha-\beta p_{1 n}$.In the first stage, there will have some consumers return the waste products, and the seller is responsible to recycle the waste products.

Then, the manufacturers will repurchase these waste products from the sellers for re-manufacturing, and back to the market. Because the different acceptance between re-manufacturing products and new products, so two kinds of products priceare not the same. The demand for new products' equation in the second stage is expressed: $q_{2 n}=\alpha-\beta p_{n}-\gamma\left(p_{n}-p_{r}\right)$.The demand for re-manufacturing products' equation

expressed: $q_{r}=\left\{\begin{array}{ll}\gamma\left(p_{n}-p_{r}\right) & p_{r}<p_{n} \\ 0 & p_{r} \geq p_{n}\end{array} \quad . \alpha\right.$ will denote potential market share. $\beta$ will denote the sensitivity of the market demand to price. $\gamma$ will denote free coefficient, which express consumers hesitate choose between new products and manufacturing products.

Assumption 5. We suppose the same of total demand products in two stages. While new products and manufactured goods' sale price are different, the total number of two products in the second stage is still the same with the first production cycle only sell new products.

\section{SUPPLY CHAIN MODELS WITH MANUFACTURING AND RE-MANUFACTURING}

This section presents only manufacture new products in two stages (Model M, Figure 1a), the closed-loop supply chain with the retailer collecting used products (Model R, Figure. 1b)

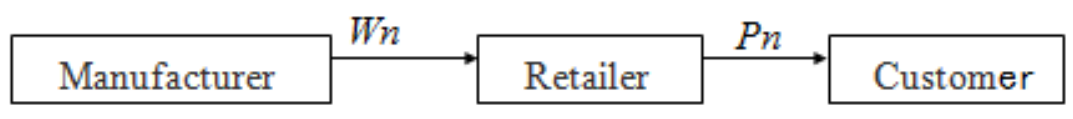

(a) Model M 


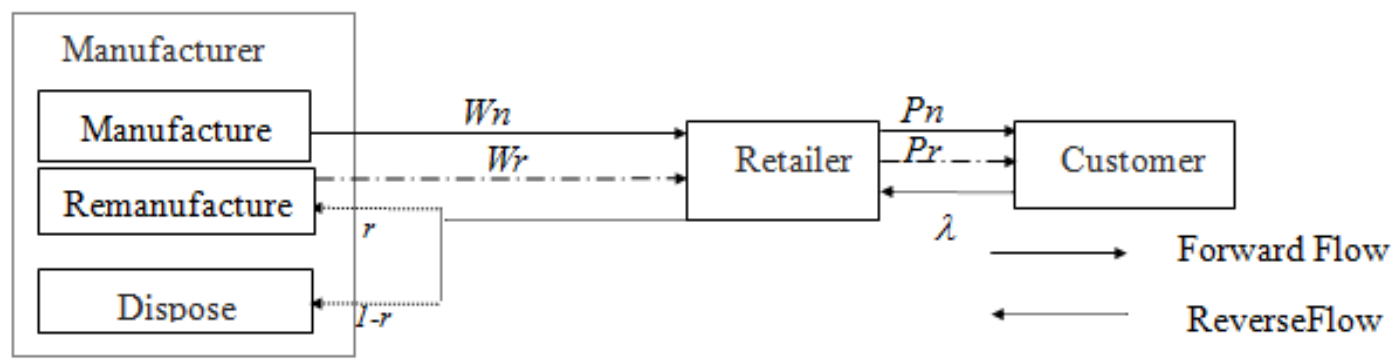

(b) Model $\mathrm{R}$

Figure 1 Closed-loop supply chain models with or without re-manufacturing

A. Model M-Only Manufacture New products In Two Stages

In this situation, Manufacturer only manufactures new products. Hence, the manufacturer and retailer optimize:

$$
\begin{gathered}
\pi_{m}^{N}=2\left(w_{n}-c_{n}\right)\left(\alpha-\beta p_{n}\right) \\
\pi_{r}^{N}=2\left(p_{n}-w_{n}\right)\left(\alpha-\beta p_{n}\right)
\end{gathered}
$$

The simultaneous solution of the first-order conditions results in $w^{*}=\frac{\alpha+\beta c_{n}}{2 \beta}$ and $p^{*}=\frac{3 \alpha+\beta c_{n}}{4 \beta}$.

According to $w^{*}, p^{*}$ could calculate the optimal profits in this situation. The results are shown in Table 1 .

\section{B. Model R—Consider Waste Products}

Re-manufacturing In The Second Stage

According to the assumption 2, manufacturer dominants the market. In other words, she limits the retail price. Hence, the manufacturer and retailer optimize:

$$
\begin{aligned}
& \max _{w_{n}, w_{r}} \pi_{\mathrm{m}}=\left(w_{n}-c_{n}\right)\left(\alpha-\beta p_{n}\right)+\left(w_{n}-c_{n}\right)\left(\alpha-\beta p_{n}-\gamma\left(p_{n}-p_{r}\right)\right) \\
& +\left(w_{r}-c_{r}\right) \times \gamma\left(p_{n}-p_{r}\right)+S(1-r)\left[\lambda\left(\alpha-\beta p_{n}\right)+\delta b\right]-B\left[\lambda\left(\alpha-\beta p_{n}\right)+\delta b\right] \\
& \quad \text { s.t. } \max _{p_{r}, p_{n, \delta}} \pi_{r}=\left(p_{n}-w_{n}\right)\left(\alpha-\beta p_{n}\right)+\left(p_{n}-w_{n}\right)\left(\alpha-\beta p_{n}-\gamma\left(p_{n}-p_{r}\right)\right) \\
& \quad+\left(p_{r}-w_{r}\right) \times \gamma\left(p_{n}-p_{r}\right)-c_{0} \delta^{2}+B\left[\lambda\left(\alpha-\beta p_{n}\right)+\delta b\right]
\end{aligned}
$$

According to the Hesse matrix, we know that the objective function is jointly concave in and the retailer's first-order conditions characterize the unique best response:

$$
\begin{gathered}
p_{n}^{*}=\frac{2 \alpha+2 \beta w_{n}-\beta \lambda B}{4 \beta} \\
p_{r}^{*}=\frac{2 \alpha+2 \beta w_{r}-\beta \lambda B}{4 \beta} \\
\delta^{*}=\frac{b B}{2 c_{\mathrm{o}}}
\end{gathered}
$$

We can use the above results, the manufacturer's first-order conditions characterize the unique best response,

$$
w_{n}^{*}=\frac{\alpha}{2 \beta}+\frac{c_{n}+\lambda B}{2}-\frac{(1-r) \lambda S}{4}
$$

$$
w_{r}^{*}=\frac{\alpha}{2 \beta}+\frac{c_{r}+\lambda B}{2}-\frac{(1-r) \lambda S}{4}
$$

Through the optimal sale price and Wholesale price, we can easily calculate the profits about manufacturer and retailer:

$$
\begin{aligned}
& \pi_{m}^{*}=\frac{\left[2 \alpha-2 \beta c_{n}+(1-r) \lambda \beta S\right]^{2}}{16 \beta}+\gamma \frac{\left(c_{n}-c_{r}\right)^{2}}{8}+[S(1-r)-B] \delta b, \\
& \pi_{r}^{*}=\frac{\left[2 \alpha-2 \beta c_{n}+(1-r) \lambda \beta S\right]^{2}}{32 \beta}+\gamma \frac{\left(c_{n}-c_{r}\right)^{2}}{16}-c_{0} \delta^{2}+B \delta b,
\end{aligned}
$$

the results are listed in Table 1 in Appendix A.

\section{ANALYSIS AND RESULTS}

Based on the results summarized in Table1, some interesting observations can be made on the closed-loop supply chain structures.

Proposition 1.The wholesale price and the retail price under different models are as follows: 


$$
w^{*}<w_{n}^{*}, p^{*}>p_{n}^{*}>p_{r}^{*} \text {. }
$$

In fact, as the table 1 shows: For manufacturer, the wholesale price of only manufacturing new products in the $\mathrm{M}$ Model is less than the price of producing new products and re-manufacturing products in the $\mathrm{R}$ Model. Due to the manufacturer choose to reuse the waste products, which leads manufacturer to reduce the cost of the product. Therefore, the retailer should set a lower sales price. However, we can learn that wholesale price is also limited by the recycling price in this paper.

Proposition2. The results of comparison about manufacturer and retailer's profits under different models are as follows: $\pi_{m}^{*}>\pi_{m}^{N^{*}}, \pi_{r}^{*}>\pi_{r}^{N^{*}}$.

Although it will lead to such as the recycling cost increased when manufacturer choose the Model R, which can also get considerable income. In particular, it can help us to make full use of waste resources and to protect the environment.

Proposition 3. The wholesale price is related with the cost of products, the recycling price, and the sensitivity of consumer for retail price.

The formulas (8) and (9) are shown that the recycling price of waste products is increasing and the wholesale price increasing. And the formula (7) is shown that the wholesale price is increasing while the market requires decreasing.

\section{CONCLUSION}

In this paper, we focus on the product price of the re-manufacturing closed-loop supply chain, which consists a single manufacturer and seller. We assume that the manufacturer dominates the market in the two stages, in which only new products be manufactured in the first stage(Model M), both of the two kinds of products can be manufactured in the second stage(Model R). The results show that, in the second stage, sale prices of new products and re-manufacturing products are both lower than only produce new products. When we choose the former, it will obtain more benefits. Furthermore, the retailer will do better when more money was paid for waste products. And the manufacturer's wholesale price is determined by the cost of new products, recycled products and recycling price.

However, there are some limitations to this study that require further examination and additional research. First, we assume that the total market demand remains unchanged, which may not conform to the actual situation in market. Second, we assume that a single manufacturer and seller in closed-loop supply chain, while there are actually many manufacturers and retailers in the market. Third, we assume that manufacturers lead the market in order to make the result more precise, while it will complex than this in fact. If we change assumptions above, it would lead different price strategies.

Appendix A

In order toconnivancecompare, we summarize the results into Table 1 as follow:

TABLE I. COMPARISON OF SUPPLY CHAIN MODELS

\begin{tabular}{|c|c|c|c|}
\hline \multirow{2}{*}{$\begin{array}{c}\text { Price decision } \\
\text { and profits }\end{array}$} & \multicolumn{2}{|c|}{$\begin{array}{c}\text { Supply Chain With Re-manufacturing } \\
\text { (Model R) }\end{array}$} & $\begin{array}{c}\text { Supply Chain } \\
\text { Without } \\
\text { Re-manufacturi } \\
\text { ng } \\
\text { (Model M) }\end{array}$ \\
\cline { 2 - 5 } Wholesale price & New Products & Re-manufacturing Products & New Products \\
\hline \multirow{2}{*}{ Sale price } & $\frac{\alpha+\beta c_{n}}{2 \beta}+\frac{\lambda(2 B-S+r S)}{4}$ & $\frac{\alpha+\beta c_{r}}{2 \beta}+\frac{\lambda(2 B-S+r S)}{4}$ & $\frac{\alpha+\beta c_{n}}{2 \beta}$ \\
\hline \multirow{2}{*}{ Profits } & $\frac{3 \alpha+\beta c_{n}}{4 \beta}-\frac{\lambda S(1-r)}{8}$ & $\frac{3 \alpha+\beta c_{r}}{4 \beta}-\frac{\lambda S(1-r)}{8}$ & $\frac{3 \alpha+\beta c_{n}}{4 \beta}$ \\
\cline { 2 - 5 } & Manufacturer & $\frac{\left(\alpha-\beta c_{n}\right)^{2}}{4 \beta}+\frac{[\lambda \beta S(1-r)]^{2}}{16 \beta}+\gamma \frac{\left(c_{n}-c_{r}\right)^{2}}{8}+[S(1-r)-B] \delta b$ & $\frac{\left(\alpha-\beta c_{n}\right)^{2}}{4 \beta}$ \\
\hline \multirow{2}{*}{ Retailer } & $\frac{\left(\alpha-\beta c_{n}\right)^{2}}{8 \beta}+\frac{[\lambda \beta S(1-r)]^{2}}{32 \beta}+\gamma \frac{\left(c_{n}-c_{r}\right)^{2}}{16}-c_{0} \delta^{2}+B \delta b$ & $\frac{\left(\alpha-\beta c_{n}\right)^{2}}{8 \beta}$ \\
\hline
\end{tabular}

\section{ACKNOWLEDGEMENT}

This paper was financially supported by the major humanities and social science project of Zhejiang Provincial Department of Education (2014GH016).

\section{REFERENCES}

[1] Guide V D R, Wassenhove L N V. Business aspects of closed-loop supply chains, Pittsburgh: Carnegie Mellon University Press, 2003.
[2] Da Q L, Huang Z Q,Zhang Q. Current and future studies on structure of the reverse logistics system: A review [J]. Management Science, Vol.12, no.1, pp. 131-138, 2004.

[3] Savaskan R C, Bhattacharya S, Wassenhove L N V, "Closed-loop supply chain models with product re-manufacturing", Management Science, vol.50, no.2, pp.239- 252, 2004.

[4] Heese H S, Cattani S K, FerrerG,et al., "Competitive advantage through take-back of used products", European J of Operational Research, vol.164, no.1, pp. 143-157, 2005.

[5] FFerguson M, Toktay L B. The effect of competition on recovery 
strategies $[\mathrm{J}]$. Production and Operations Management, vol.15, no.3, pp.351-368, 2006

[6] Huang Z Q,Da Q L, "Study on efficiency of serial supply chains with remanufacture". Journal of Management Sciences in China, 2006.

[7] Wang Wenbin, DaQingli, "Production and pricing strategy of closed-loop supply chain considering market segmentation", Control and Decision, vol.24, pp.375-379, May 2009.

[8] Liang Y, Pokharel S, Lim G H, "Pricing used products for remanufacturing", European Journal of Operational Research, vol.193, no.2, pp. 390 - 395, 2009.

[9] Xie Jiaping, Wang Shuang, "Optimal production decision model of the manufacturing/remanufacturing system in the heterogeneous market", Journal of Management Sciences in China, vol.14, no.3, pp. $24-33,2011$.

[10] GiutiniR, Gaudette K, "The economics of remanufacturing under limited component durability and finite product life cycles", Management Science, vol.53, no.1, pp 88-100, 2007. 